\title{
Dual Blockade of the Renin-Angiotensin System in Diabetic Nephropathy
}

Mordchai Ravid, MD, FACP

$\mathrm{T}$ he accelerated progression of atherosclerosis in diabetes is most probably the end result of the cumulative impact of the major risk factors that are more prevalent in diabetic subjects, namely obesity and dyslipidemia, the derangement in carbohydrate metabolism (hyperglycemic environment, hyperinsulinism, and insulin resistance), a prothrombotic tendency, and, perhaps most important, microalbuminuria and hypertension (1-5). At least two additional cardiovascular risk factors are probably more pronounced in diabetes; they are endothelial dysfunction (6) and an inflammatory reaction in the affected blood vessels mediated by the proinflammatory interleukins and expressed by elevated levels of C-reactive protein (7).

Microalbuminuria is often the first clinical manifestation of early microvascular derangement. In type 2 diabetes, it is the hallmark of subsequent diabetic nephropathy and a surrogate marker of cardiovascular disease and increased cardiovascular mortality (8). Furthermore, the presence of microalbuminuria predicts a worse outcome after percutaneous coronary intervention. The 2-year mortality after percutaneous coronary intervention in diabetic patients with microalbuminuria was increased by $85 \%$ compared with individuals with normal urinary albumin excretion (9). Microalbuminuria is associated with echocardiographic evidence of left ventricular hypertrophy and identifies overall cardiovascular risk also in hypertensive nondiabetic patients $(10,11)$. It is therefore mandatory to screen all diabetic as well as nondiabetic hypertensive patients for the presence of microalbuminuria. Indeed, all the relevant professional associations have included annual screening for microalbuminuria in their recommendations $(12,13)$. Treatment strategies aimed at reducing urinary albumin excretion were found to be effective in retarding the progression of renal disease, as manifested by prolongation of the time to doubling of serum creatinine and postponement of end-stage renal disease and the need to renal replacement therapy $(14-17)$.

Furthermore, the magnitude of early decline in albuminuria in response to a given therapeutic intervention is a reliable predictor of subsequent renoprotective effect of this therapy (18).

In type 1 diabetes, many patients who initially develop microalbuminuria subsequently revert to normoalbuminuria $(18,19)$; therefore, the association between spontaneous or therapy-induced changes in albumin excretion rate and the subsequent progression of nephropathy is less clear (20).

The elucidation of the infrastructure of the renin-angiotensin-aldosterone system and the development of specific inhibitors of various steps in its biochemical cascade have emerged as the most significant means to control blood pressure, reduce cardiovascular sequelae, and retard the decline in renal function in all hypertensive patients and especially in diabetic patients $(21,22)$. The four drug classes target angiotensin II and aldosterone through either direct or complimentary mechanisms. The renin inhibitors reduce the conversion of angiotensinogen to angiotensin I, and ACE inhibitors block the conversion of angiotensin I to the active peptide angiotensin II and increase the availability of bradykinin. Angiotensinreceptor blockers (ARBs) selectively an-

From the Sackler Faculty of Medicine, Tel Aviv University, Maynei Hayeshua Medical Center, Bnei Brack, Israel.

Corresponding author: Mordchai Ravid, ravid@mhmc.co.il.

The publication of this supplement was made possible in part by unrestricted educational grants from Eli Lilly, Ethicon Endo-Surgery, Generex Biotechnology, Hoffmann-La Roche, Johnson \& Johnson, LifeScan, Medtronic, MSD, Novo Nordisk, Pfizer, sanofi-aventis, and WorldWIDE.

DOI: $10.2337 / \mathrm{dc} 09-\mathrm{S} 349$

C 2009 by the American Diabetes Association. Readers may use this article as long as the work is properly cited, the use is educational and not for profit, and the work is not altered. See http://creativecommons. org/licenses/by-nc-nd/3.0/ for details.

tagonize angiotensin II at the ATl receptors and increase the activation of the AT2 receptors. Finally, the aldosterone-receptor blockers reduce the metabolic and the proliferative effects of aldosterone (Fig. 1).

When appropriate dosage was used, long-term studies in hypertensive and in diabetic patients could demonstrate little if any difference in blood pressure lowering and in the cardiovascular as well as the renoprotective efficacy between the various renin-angiotensin-aldosterone system inhibiting or blocking agents $(23,24)$; there may, in fact, be a small advantage of ACE inhibitors over ARBs, at least as far as cardiovascular protection is considered (25). There is little doubt that the major predictive factor of subsequent cardiovascular as well as kidney protection is the degree of blood pressure lowering (2630). Control of hypertension is, therefore, paramount to postpone or possibly prevent end-stage renal disease and cardiovascular complications.

The complexity of the renin-angiotensinaldosterone system and the proven efficacy of the various blocking and inhibiting agents stimulated the design of clinical trials to test the hypothesis that, in such a complex system, combining the effect of two or more drugs may offer better results than a single intervention. Diabetic nephropathy was the natural choice as the research platform because of the high-risk profile of these patients, the well-known downhill clinical course all the way to end-stage kidney, and, therefore, the ability to clearly define and demonstrate the efficacy of therapeutic interventions. In a high-risk model, any therapeutic effect is augmented and may be later applicable in other lower-risk constellations. Abe et al. (31) in Japan examined the renoprotective effect of the addition of an ARB (losartan) or an ACE inhibitor to conventional antihypertensive regimens or to ACE inhibitor-based regimens in patients with diabetic nephropathy. The drug doses were titrated to obtain predetermined blood pressure reduction goals. They found no advantage of dual reninangiotensin system (RAS) blockade over the combination of a single RAS blocker with conventional antihypertensive regimens. These results corroborate the con- 


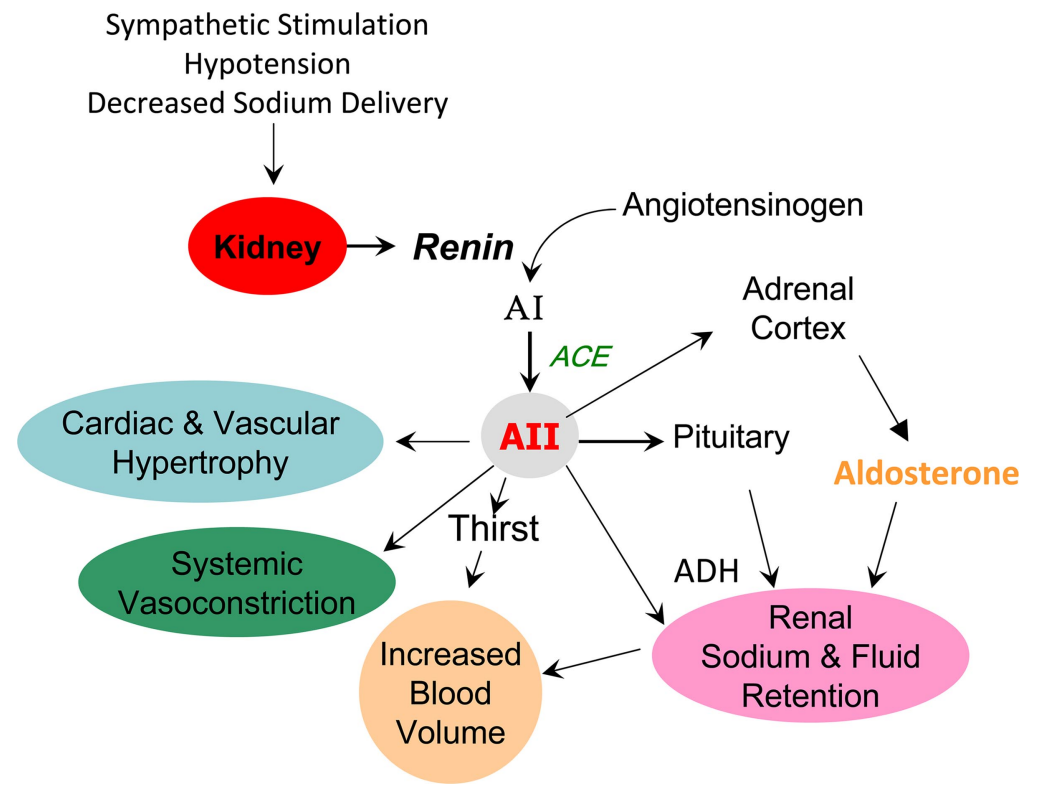

Figure 1-The renin-angiotensin-aldosterone cascade and the various options to block the system. AI, angiotensin I; AII, angiotensin II.

clusions of a large study in high-risk hypertensive patients (32) where, after 3.2 years' follow-up, candesartan-based regimens rendered equipotent cardiovascular and renal protection to amlodipinebased regimens. In a rather short-term 20-week study, the IMPROVE investigators found no advantage of dual RAS blockade with irbesartan and ramipril over ramipril alone in reducing albuminuria in high-risk hypertensive subjects (33).

So far, the largest and best controlled study that compared the antihypertensive effect and cardiovascular and renal protection in high-risk hypertensive and diabetic patients was the ONTARGET trial (24). In this prospective study, $>25,000$ patients were randomized to antihypertensive treatment protocols based on an ARB (telmisartan), an ACE inhibitor (ramipril), or the combination of both. After a mean follow-up period of 56 months, telmisartan was equivalent to ramipril in all aspects (albeit with a better side-effect profile). The combination of the two drugs was associated with more adverse events without an increase in benefit.

The results of five parallel-group studies and 16 crossover studies comprising together 654 patients and comparing dual RAS blockade with ARBs and ACE inhibitors to either agent alone were pulled together by MacKinnon et al. (34). They concluded that the dual therapy was safe in patients with proteinuric renal dis- ease. The dual blockade was associated with a minor increase in serum potassium and a small decline in glomerular filtration rate, as compared with each of the single agents. Also, the combination therapy was associated with a significant further decrease in proteinuria in diabetic as well as nondiabetic patients. Definite end points of renoprotection could not be assessed in this analysis because of the small number of patients and the short follow-up period. Kunz et al. (35) extracted, in hitherto the largest meta-analysis, the results of 110 studies in which the effect of either an ACE inhibitor or an ARB on proteinuria in renal disease was compared with the combination of the two agents. All the studies were short-lived and comprised together 6,181 patients. In 72 studies, the follow-up periods were only 1-4 months, whereas in the remaining 38 studies, the follow-up lasted 5-12 months. As expected, both ARBs and ACE inhibitors reduced proteinuria compared with placebo or calcium-channel blockers and were equipotent when compared with each other. The combination of ARBs and ACE inhibitors further reduced proteinuria more than either agent alone. The ratio of means for combination therapy versus ARBs was 0.76 (CI 0.68-0.85) over 1-4 months and 0.75 (CI $0.61-$ $0.92)$ over 5-12 months. For combination therapy versus ACE inhibitors, the ratio of means was 0.78 (CI $0.72-0.84$ ) over 1-4 months and 0.82 (CI 0.67 1.01) over 5-12 months (Table 1). The
Table 1-ACE inhibitors and ARBs: comparative effect on proteinuria in parallel-group randomized studies of 5-12 months' duration: a meta-analysis

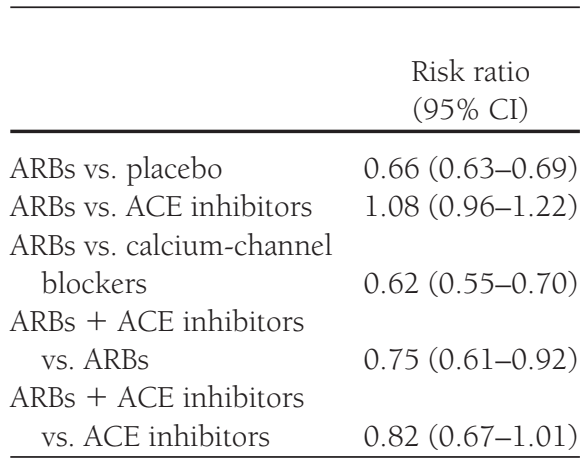

studies included in the meta-analysis were small, of short duration, and of variable quality. Therefore, the uncertainty regarding the important end points, mainly preservation of kidney function and cardiovascular protection, could not be resolved. Also, the issues of possible preponderance of adverse effects of the dual therapy and the stability of the therapeutic effect over time remained undecided, thus limiting the applicability of the results to clinical practice.

The theoretical added benefit of double renin-angiotensin-aldosterone system blockade was further explored using the remaining drug classes, namely aldosterone receptor antagonists and the new renin inhibitor aliskiren. Based on the wellknown observation of the aldosteroneescape phenomenon under single RAS blockade with either an ACE inhibitor or an ARB (36), Schjoedt et al. (37) examined the effect of spironolactone as an add-on agent to other RAS blockers on nephritic-range albuminuria in patients with diabetic nephropathy. The addition of low-dose $(25 \mathrm{mg}$ ) spironolactone resulted in a further decline of $32 \%$ in albumin excretion rate. The short 2-month duration of this study precludes any conclusions as to renoprotection. A recent systematic review (38) suggested that adding aldosterone blockers to ACE inhibitors or to ARBs significantly reduced albuminuria. The long-term safety of this regimen cannot be determined however.

The novel renin inhibitor aliskiren was tested, both alone or in combination with ACE inhibitors, in animal models of diabetic nephropathy and in short-term clinical studies on hypertensive subjects $(39,40)$. This agent is probably equipotent to the other major drugs in lowering blood pressure and in reducing protein- 
uria. There are, as yet, no long-term studies that would permit a discussion on clinically relevant effects.

Management of hypertension is, no doubt, the most significant intervention in preventing diabetic renal as well as cardiovascular disease. Tight control of blood pressure to recommended target levels affords long-term complicationfree periods for diabetic patients. There seems to be a wide consensus that RAS blocking agents offer better renal protection than other drugs with equivalent antihypertensive potency. However, despite numerous studies, there is no real evidence that using double blockade offers an advantage in clinically relevant end points over the already time-honored single RAS blockade in combination with thiazide diuretics and calcium channel blockers.

Acknowledgments - No potential conflicts of interest relevant to this article were reported.

\section{References}

1. Harris MI, Eastman RC. Is there a glycemic threshold for mortality risk. Diabetes Care 1998;21:331-332

2. Stevens RJ, Coleman RL, Adler AI, Stratton IM, Matthews DR, Holman RR. Risk factors for myocardial infarction case fatality and stroke case fatality in type $2 \mathrm{di}$ abetes: UKPDS 66. Diabetes Care 2004; 27:201-207

3. Pastor-Barriuso R, Banegas JR, Damian J, Appel LJ. Systolic blood pressure, diastolic blood pressure and pulse pressure: an evaluation of their joint effect on mortality. Ann Intern Med 2003;139:731739

4. Tooke JE. Possible pathophysiological mechanisms for diabetic angiopathy in type 2 diabetes. J Diabetes Complications 2000;14:197-200

5. Knight EL, Kramer HM, Curhan GC. High-normal blood pressure and microalbuminuria. Am J Kidney Dis 2003; 41:588-595

6. Preik M, Kelm M, Rosen P, Tschope D, Strauser BE. Additive effect of coexistent type 2 diabetes and arterial hypertension on endothelial dysfunction in resistance arteries of human forearm vasculature. Angilogy 2000;51:545-554

7. Messerli AW, Seshadri N, Pearce GL, Sachar R, Hoogwerf BJ, Sprecher DL. Relation of albumin/creatinine ratio to Creactive protein and the metabolic syndrome. Am J Cardiol 2003;92:610-612

8. Gerstein HC, Mann JF, Yi Q, Zinman B, Dinneen SF, Hoogwerf BJ, Halla JP, Young J, Rashkow A, Joyce C, Yusuf S, HOPE Study Investigators. Albuminuria and risk of cardiovascular events, death, and heart failure in diabetic and nondiabetic individuals. JAMA 2001;286:421-426

9. Marso SP, Ellis SG, Tuzcu M, Whitlow PL, Franco I, Raymound RE, Topol EJ. The importance of proteinuria as a determinant of mortality following percutaneous coronary revascularization in diabetics. J Am Coll Cardiol 1999;33:1269-1277

10. Wachtell K, Palmieri V, Olsen MH, Bella JN, Alto T, Dahlof B, Gerdts E, Wright JR, Papademitriou V, Mogensen CE, BorchJohnsen K, Ibsen H, Devereux RB. Urine albumin/creatinine ratio and echocardiographic left ventricular structure and function in hypertensive patients with electrocardiographic left ventricular hypertrophy: the LIFE study Losartan Intervention for Endpoint Reduction. Am Heart J 2002;143:319-326

11. Leoncini G, Sacchi G, Viazzi F, Ravera M, Parodi D, Ratto E, Vettoretti S, Tomolillo C, Deferrari G, Pontremoli R. Microalbuminuria identifies overall cardiovascular risk in essential hypertension: an artificial neural network-based approach. J Hypertens 2002;20:1315-1321

12. Kaplan NM. Management of hypertension in patients with type 2 diabetes mellitus: guidelines based on current evidence. Ann Intern Med 2001;135:1079-1083

13. Bakris GL, Williams M, Dworkin L, Elliot WT, Epstein M, Toto R, Tuttle K, Douglas J, Husueh W, Sowers J. Preserving renal function in adults with hypertension and diabetes: a consensus approach: National Kidney Foundation Hypertension and Diabetes Executive Committees Working Group. Am J Kidney Dis 2000;36:646661

14. Berl T, Hunsicker LG, Lewis JB, Pfeffer MA, Porush JG, Rouleau JL, Drury PL, Esmatjes E, Hricik D, Parikh CR, Raz I, Vanllile PP, Wiegmann TB, Wolfe BM, Locatelli F, Goldhaber SZ, Lewis EJ. Cardiovascular outcomes in the irbesartan diabetic nephropathy trial of patients with type 2 diabetes and overt nephropathy. Ann Intern Med 2003;138:542-549

15. Lewis EJ, Hunsicker LG, Clark WR, Berl T, Pohl MA, Lewis JB, Ritz E, Atkins RC, Rohde R, Raz I. Renoprotective effect of the angiotensin-receptor antagonist irbesartan in patients with nephropathy due to type 2 diabetes. N Engl J Med 2001; 345:851-861

16. Brenner BM, Cooper ME, De Zeeuw D, Kean WF, Mitch WE, Parving HH, Remuzzi G, Snapinn SM, Zhang Z, Shahinfar S. Effects of losartan on renal and cardiovascular outcomes in patients with type 2 diabetes and nephropathy. N Engl J Med 2001;345:861-869

17. Parving $\mathrm{HH}$, Lehnert $\mathrm{H}$, BrochnerMortensen J, Gomis R, Andersen S, Arner P. The effect of irbesartan on the development of diabetic nephropathy in patients with type 2 diabetes. N Engl J Med 2001; 345:870-878
18. Steinke JM, Sinaiko AR, Kramer MS, Suissa S, Chavers BM, Mauer M. The early natural history of nephropathy in type 1 diabetes. III. Predictors of 5-year urinary albumin excretion rate patterns in initially normoalbuminuric patients. Diabetes 2005;54:2164-2171

19. Kosia N, Sarafidis PA, Bakris GA. Microalbuminuria. Clin Lab Med 2006;26: 635-653

20. Jerums G, Panagiotopoulos S, Premaratne E, Power DA, MacIsaac RJ. Lowering proteinuria in response to antihypertensive therapy predicts improved renal function in late but not in early diabetic nephropathy: a pooled analysis. Am J Nephrol 2008;28:614-627

21. de Zeeuw D, Remuzzi G, Parving HH, Keane WF, Zhang Z, Shahinfar S, Snapinn S, Cooper ME, Mitch WE, Brenner BM. Proteinuria, a target for renoprotection in patients with type 2 diabetic nephropathy: lessons from RENAAL. Kindey Int 2004;65:2309-2320

22. Toto RD. Proteinuria reduction: mandatory consideration or option when selecting an antihypertensive agent? Curr Hypertens Rep 2005; 7:374-378

23. Yusuf S, Sleight P, Pogue J, Bosch J, David $R$, Dagenais $G$. Effects of an angiotensinconverting-enzyme inhibitor, ramipril, on cardiovascular events in high-risk patients. N Engl J Med 2000;342:145-153

24. ONTARGET Investigators. Telmisartan, ramipril, or both in patients at high risk for vascular events. N Engl J Med 2008; 358:1547-1559

25. Dickstein K, Kjekshus J. Effects of losartan and captopril on mortality and morbidity in high-risk patients after acute myocardial infarction: the OPTIMAAL randomized trial. LANCET 2002;360: $752-760$

26. McMurray JJ, Pfeffer MA, Swedberg K, Dzau VJ. Which inhibitor of the reninangiotensin system should be used in chronic heart failure and acute myocardial infarction? Circulation 2004;110: 3281-3288

27. David BM, Douglas CM, Lori AO, Manesh RP, Uptal DP, Meenal BP, Benjamin P, Gregory PS, Rebecca NG. Systematic review: comparative effectiveness of angiotensin-converting enzyme inhibitors and angiotensin II receptor blockers for treating essential hypertension. Ann Intern Med 2008;148:16-29

28. Barnett AH, Bain SC, Bouter P, Karlberg B, Madsbad S, Jervell J, Mustonen J, Diabetics Exposed to Telmisartan and Enalapril Study Group. Angiotensin-receptor blockade versus converting-enzyme inhibition in type 2 diabetes and nephropathy. N Engl J Med 2005;352:1731

29. Bakris GL, Weir MR, Shanifar S, Zhang Z, Douglas J, van Dijk DJ, Brenner BM, RENAAL Study Group. Effects of blood pressure level on progression of diabetic 


\section{Ravid}

nephropathy: results from the RENAAL Study. Arch Intern Med 2003;63:15551565

30. Knudsen ST, Andersen NH, Poulsen SH, Eiskjaer H, Hansen KW, Helleberg K, Poulsen PL, Mogensen CE. Pulse pressure lowering effect of dual blockade with candesartan and lisinopril vs. high-dose ACE inhibition in hypertensive type 2 diabetic subjects: a CALM II Study post-hoc analysis. Am J Hypertens 2008;21:172-176

31. Abe H, Minaoguchi S, Ohashi H, Murata I, Minagawa T, Okuma T, Yokoyama H, Takatsu H, Takaya T, Nagano T, Osumi Y, Kakami M, Tsukamoto T, Tanaka T, Hiei $\mathrm{K}$, Jujiwara H. Renoprotective effect of the addition of losartan to ongoing treatment with an angiotensin converting enzyme inhibitor in type-2 diabetic patients with nephropathy. Hypertens Res 2007;39: 929-935

32. Ogihara T, Nakao K, Fukui T, Fukiyama K, Ueshima K, Oba K, Sato T, Saruta T, Candesartan Antihypertensive Survival Evaluation in Japan Trial Group. Effects of candesartan compared with amlodipine in hypertensive patients with high cardio- vascular risks: candesartan antihypertensive survival evaluation in Japan trial. Hypertenion 2008;51:393-398

33. Bakris GL, Ruilope L, Locatelli F, Ptaszynska A, Peiske B, de Champlain J, Weber MA, Raz I. Treatment of microalbuminuria in hypertensive subjects with elevated cardiovascular risk: results of the IMPROVE trial. Kidney Int 2007;72:879-885

34. MacKinnon M, Shurraw S, Akbari A, Knoll GA, Jaffey J, Clark HD. Combination therapy with an angiotensin receptor blocker and an ACE inhibitor in proteinuric renal disease: a systematic review of the efficacy and safety data. Am J Kidney Dis 2006; 48:8-20

35. Kunz R, Friedrich C, Wolbers M, Mann JF. Meta-analysis: effect of monotherapy and combination therapy with inhibitors of the renin angiotensin system on proteinuria in renal disease. Ann Intern Med 2008; 148:30-48

36. Athyros VG, Mikhailidis DP, Kakafika AI, Tziomalos K, Karagniannis A. Angiotensin II reactivation and aldosterone escape phenomena in rennin-angiotensin-aldosterone system blockade: is oral renin in- hibition the solution? Expert Opin Pharmacother 2007;8:529-535

37. Schjoedt KJ, Jacobsen P, Rossing K, Boomsma F, Parving HH. Dual blockade of the rennin-angiotensin-aldosterone system in diabetic nephropathy: the role of aldosterone. Horm Metab Res 2005; (Suppl. 1):4-8

38. Bomback AS, Kshirsagar AV, Amamoo MA, Klemmer PJ. Change in proteinuria after adding aldosterone blockers to ACE inhibitors or to angiotensin receptor blockers in CKD: a systematic review. Am J Kidney Dis 2008;51:199-211

39. Matos JP, de Lourdes Rodrigues M, Ismerim VL, Bosasquevisque EM, Genelhu V, Francischetti EA. Effects of dual blockade of the rennin-angiotensin system in hypertensive, type 2 diabetic patients with nephropathy. Clin Nephrol, 2005; 64:180-189

40. Kelly DJ, Zhang Y, Moe G, Naik G, Gilbert RE. Aliskiren, a novel rennin inhibitor, is renoprotective in a model of advanced diabetic nephropathy in rats. Diabetologia 2007;50:2398-2404 